УДК $577.1+574.2$

\title{
ВАРИАЦИИ СОДЕРЖАНИЯ БИОЛОГИЧЕСКИ АКТИВНЫХ СОЕДИНЕНИЙ В РАЗЛИЧНЫХ ОРГАНАХ PLANTAGO SALSA PALL. В ЗАВИСИМОСТИ ОТ УСЛОВИЙ ПРОИЗРАСТАНИЯ
}

\author{
(C) Т.М. Гребенкина, Е.С. Богданова", В.Н. Нестеров, О.А. Розенцвет
}

\author{
Институт экологии Волжского бассейна РАН, ул. Комзина, 10, Тольятти, \\ 445003 (Россия), e-mail: cornales@mail.ru
}

\begin{abstract}
Исследовали количественные вариации содержания соединений, способных проявлять биологическую активность (полисахариды, фенольные соединения, липиды и аскорбиновая кислота) в листьях и корнях галофита Plantago salsa в зависимости от условий произрастания. Среди полисахаридов превалировала гемицеллюлоза А, затем следовали гемицеллюлоза Б, пектиновые вещества и водорастворимые полисахариды. Основную группу липидов составляли мембранные и запасные глицеролипиды. Содержание фенольных соединений на порядок выше в листьях, чем в корнях. Содержание и соотношение основных фенольных соединений, аскорбиновой кислоты менялось в зависимости от условий. Выявлены наиболее и наименее вариативные компоненты в листьях и корнях. Установлено, что распределение полисахаридов, фенольных соединений, аскорбиновой кислоты и липидов в органах растений зависит от эдафических факторов. Полученные данные могут быть полезны при разработке практических рекомендаций для сбора лекарственных растений в различных условиях произрастания.

Ключевые слова: аскорбиновая кислота, липиды, полисахариды, Plantago salsa.
\end{abstract}

\section{Введение}

Растения Plantago представляют основной род сем. Plantaginaceae Juss (подорожник). Растения этого рода отличаются большим видовым, структурным и экологическим разнообразием. Показана генетическая дифференциация и фенотипическая пластичность некоторых видов по отношению к освещенности, условиям минерального питания, влажности почвы [1]. Фитохимические исследования выявили наличие ряда соединений, обладающих широким спектром биологической активности, таких как алкалоиды [2], производные кофейной кислоты [3], кумарины [4], липиды и жирные кислоты [5], флавоноиды [6-8], иридоиды [9], полисахариды [10], стерины и органические кислоты [11].

Детальные этнофармакологические исследования Plantago major L. (подорожник большой) - наиболее распространенного вида сем. Plantaginaceae показали, что данное растение применяется нативно, а также в составе препаратов, обладающих иммуномодулирующим и противоопухолевым эффектом [12]. В мировой практике известны и другие виды, являющиеся фармакопейными. Например, в Британскую

Гребенкина Татьяна Михайловна - кандидат

биологических наук, научный сотрудник лаборатории «Экологическая биохимия»,

e-mail:matane4ka@yandex.ru

Богданова Елена Сергеевна - кандидат биологических наук, научный сотрудник лаборатории «Экологическая биохимия», e-mail: cornales@mail.ru

Нестеров Виктор Николаевич - кандидат

биологических наук, научный сотрудник лаборатории

«Экологическая биохимия», e-mail: nesvik1@mail.ru

Розенцвет Ольга Анатольевна - доктор биологических наук, ведущий научный сотрудник лаборатории «Экологическая биохимия», e-mail: olgarozen55@mail.ru фармакопею, кроме вида $P$. major, внесены виды P. lanceolata L, P. afra L. (P. psillium L,) и P. psillium, в Американскую - P. psillium, в Японскую $P$. asiatica L. (P. psillium), в Китайскую - P. major и $P$. psillium. В Германии лекарственными препаратами на основе растений вида $P$. psillium являются непосредственно его семена, а также гранулированная лекарственная форма «Агиолакс». В Словении из экстракта растений вида $P$. lanceolata готовят препарат «Гербион сироп подорожника», в Германии - «Доктор Тайсс сироп с подорожником».

\footnotetext{
* Автор, с которым следует вести переписку.
} 
В Индии растения P. ovata Forssk. используются в производстве аюрведического средства «Исабгол» [13]. Молотые семена растений этого вида входят в состав пакистанского препарата «Файберлекс», а оболочка семян - активный компонент германского препарата «Мукофальк» [14].

Концентрация биологически активных соединений в растениях, включая виды Plantago, зависит от природно-климатических условий. В связи с этим полагают, что изучение видов рода Plantago в своей естественной среде должно быть связано с сопутствующим исследованием условий, в которых данные виды формировались [1].

Растения P. salsa Pall. относятся к экологически специализированной группе растений, которые произрастают на засоленных лугах, солончаках, обнажениях известняка и мела и являются солеустойчивыми растениями - галофитами. В наших предыдущих исследованиях показано, что растения $P$. salsa, подобно другим представителям рода, содержат ряд веществ, способных проявлять биологическую активность. К их числу относятся полисахариды, фенольные соединения, аскорбиновая кислота, липиды, жирные кислоты и др. [5-8].

Целью данной работы стало изучение особенностей изменения этих соединений в растениях P. salsa в зависимости от условий произрастания.

\section{Экспериментальная часть}

Растения отбирали единовременно в августе 2012 г. на территории Самарской области, на площадках размером $10 \times 10 \mathrm{~m}^{2}$, расположенных на двух участках: П-1 - с. Большая Каменка, Шенталинский р-н

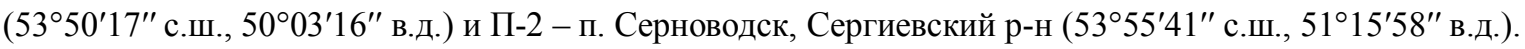

Образцы почвы, отобранные на глубине 15-20 см, исследовали на содержание кислотности, влажности и минерального остатка почвенной вытяжки (табл. 1) [15].

Общие аналитические методы. Для биохимического анализа использовали листья и корни из 5-8 растений, составляли три независимых биологических пробы (2-4 г сырой массы). Деферментацию образцов проводили кипящим изопропанолом и до анализа хранили в темном холодном месте.

Липиды экстрагировали трижды смесью хлороформа и метанола $(1: 2 \mathrm{v} / \mathrm{v})$ с одновременным механическим разрушением тканей при помощи стеклянных шариков. Объединенные экстракты отмывали от нелипидных примесей, растворитель отгоняли на роторно-вакуумном испарителе. Количество общих липидов определяли гравиметрически после полного удаления растворителей.

Разделение и количественное определение липидов осуществляли, как описано в работе [16]. Для анализа фенольных соединений, полисахаридов и аскорбиновой кислоты растительное сырье высушивали до постоянного веса при температуре $45^{\circ} \mathrm{C}$. Фенольные соединения экстрагировали $96 \%$ этанолом при нагревании на кипящей водяной бане с обратным холодильником [17]. Полисахариды разделяли на водорастворимые (ВРПС), пектиновые вещества (ПВ), гемицеллюлозы А и Б (ГЦ А и ГЦ Б) согласно рекомендациям [18]. Количество аскорбиновой кислоты определяли по методу [19].

Статистика. Результаты экспериментов обрабатывали с помощью пакета офисных программ Statistica 6,0 for Windows и Microsoft Excel 2010. Результаты представлены в виде средних величин и их стандартных ошибок. Достоверность отличий оценивали с помощью параметрического критерия Стьюдента при уровне значимости $\mathrm{P}<0,05$.

Таблица 1. Характеристика почвы в местах произрастания растений $P$. salsa

\begin{tabular}{c|c|c|c}
\hline \multirow{2}{*}{ Площадки } & \multicolumn{3}{|c}{ Характеристики } \\
\cline { 2 - 4 } & влажность, \% & соленость, $\%$ & $\mathrm{pH}$ \\
\hline$\Pi-1$ & $14,95 \pm 0,63$ & $0,14 \pm 0,10$ & $9,8 \pm 0,0$ \\
$\Pi-2$ & $30,20 \pm 0,42$ & $1,56 \pm 0,18$ & $8,5 \pm 0,0$ \\
\hline
\end{tabular}

\section{Результаты и их обсуждение}

Исследование эдафических факторов показало, что почва на участке П-2 отличалась большей влажностью, соленостью и кислотностью (табл. 1).

Одним из основных биологически активных соединений растений рода Plantago являются полисахариды. Известно, что растительные полисахариды, как правило, оказывают всестороннее воздействие на организм животных и человека. Разнообразие сфер применения объясняется тем, что они действуют на 
центральные регуляторные механизмы организма, направленные на мобилизацию защитных реакций, способствуя восстановлению нормального состояния гомеостаза [20]. Как показало наше исследование, содержание полисахаридов в листьях P. salsa составляло от 742 до 769 мг/г и от 618 до 723 мг/г сухой массы в корнях. Большую часть из них представляла фракция ГЦ А (300-400 мг/г сухой массы) (рис. 1).

Концентрация ВРПС в листьях существенно выше, чем в корнях. Содержание фракций ПВ и ГЦ Б в листьях оказалось более подверженным влиянию условий произрастания по сравнению с ГЦ А и ВРПС. Так, концентрация ПВ в листьях растений, произрастающих в условиях большей солености и влажности (П-2), была в 2 раза больше, чем в растениях, произрастающих на более сухой и менее засоленной почве. Противоположная зависимость отмечена для ГЦ Б. В корнях растений П-2 содержание фракций ПВ и ГЦ Б было несколько выше, чем в растениях П-1. Как в листьях, так и корнях выявлена положительная корреляция между содержанием ПВ и влажностью почвы, что, по-видимому, связано с необходимостью удерживать воду в клетках растения.

Важными компонентами растений, с точки зрения их пищевой и лекарственной ценности, являются фенольные соединения. В растительном организме фенольные соединения, в частности флавоноиды, индивидуально или в сочетании с аскорбиновой кислотой выполняют функцию регуляторов окислительновосстановительных процессов, угнетают процессы перекисного окисления макромолекул и другие свободнорадикальные реакции. Это же свойство флавоноидов используется в косметических и медицинских препаратах для регуляции окислительных процессов [21]. Они являются одними из самых популярных растительных добавок, применяемых для улучшения памяти [22]. Накопление фенольных соединений в листьях на порядок выше, чем в корнях. Содержание этого компонента зависело от условий среды: на менее засоленной почве в листьях растений количество фенольных соединений было в 1,5 раза выше, чем в растениях произраставших в условиях большей солености (рис. 2).

Еще более существенная связь количественных параметров с условиями произрастания отмечена для аскорбиновой кислоты. Установлено, что в листьях растений, произрастающих на площадке П-1, ее содержание составляло 1,6 мг/Г сухой массы, что в 4 раза больше, чем в листьях растений, произрастающих на участке П-2 (рис. 3). В корнях растений достоверных отличий не обнаружено.

Хорошо известно пищевое, фармакологическое и косметическое применение растительных липидов - глицеролипидов и стеринов (Ст). Например, препараты, созданные на основе фосфатидилхолинов $(\Phi \mathrm{X})$, применяют для регенерации клеток печени, фосфатидилсеринов - для улучшения мозговой деятельности [23]. Выраженные поверхностно-активные свойства фосфатидилглицеринов (ФГ) используют в медицине в качестве компонента, участвующего в «доставке» лекарственного вещества [24]. Растительные Ст способствуют снижению уровня холестерина в крови человека, а также являются предшественниками для образования ряда гормонов [25]. В результате исследования мы установили, что в листьях растений в условиях засоления (П-2) концентрация полярных липидов: гликолипидов (ГЛ) и фосфолипидов (ФЛ) - была выше, чем в растениях П-1, в отличие от нейтральных липидов (НЛ) - энергетического и метаболического резерва клетки, концентрация которых была достоверно одинаковой. В корнях растений П-2 концентрация фракции ГЛ была больше в 2 раза, НЛ - в 3 раза, а содержание фракции ФЛ - достоверно одинаковым (табл. 2).
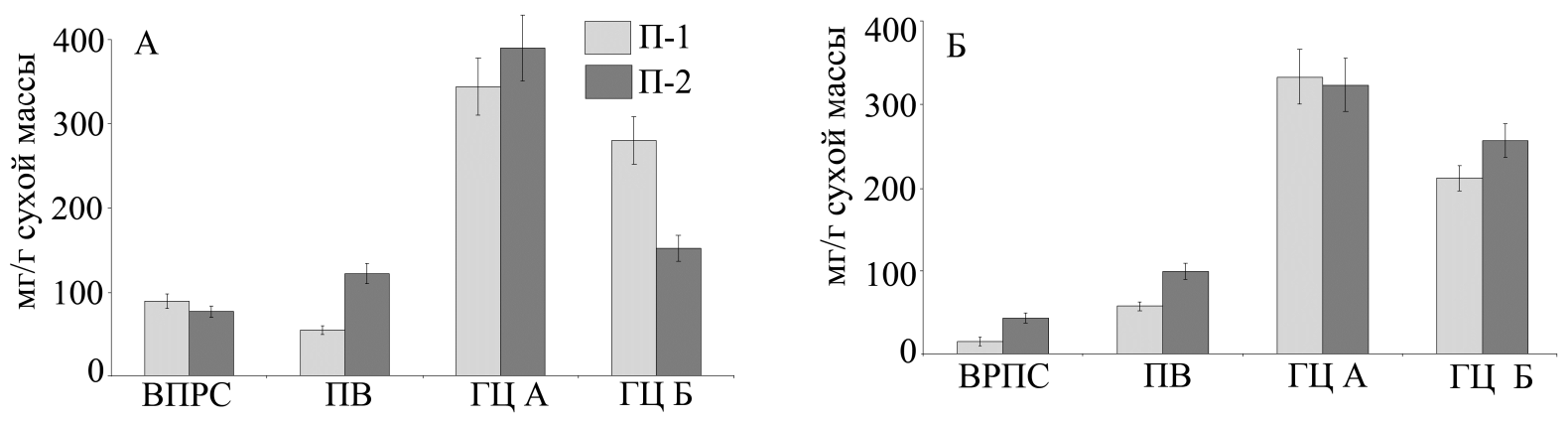

Рис. 1. Содержание полисахаридов в листьях (А) и корнях (Б) растений P. salsa, произрастающих на площадках П-1 и П-2. ВРПС - водорастворимые полисахариды, ГЦ А, ГЦ Б - гемицеллюлозы А и Б, ПВ - пектиновые вещества 




Рис. 2. Содержание фенольных соединений в листьях и корнях растений $P$. salsa, произрастающих на площадках П-1 и П-2

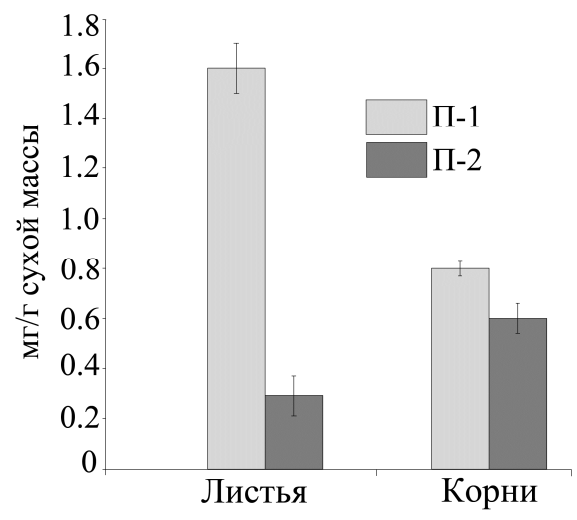

Рис. 3. Содержание аскорбиновой кислоты в листьях и корнях растений $P$. salsa, произрастающих на площадках П-1 и П-2

Таблица 2. Содержание липидов в отдельных органах растений P. salsa, произрастающих на двух площадках (мг/г сырой массы)

\begin{tabular}{c|c|c|c|c|c}
\hline \multicolumn{1}{c|}{ Вид } & Части растений & ГЛ & ФЛ & НЛ & Л \\
\hline \multirow{2}{*}{$\Pi-1$} & листья & $8,7 \pm 0,0$ & $15,3 \pm 0,7$ & $16,7 \pm 0,2$ & $40,7 \pm 0,6$ \\
& корни & $1,4 \pm 0,1$ & $30,6 \pm 3,6$ & $6,0 \pm 0,4$ & $38,0 \pm 1,2$ \\
\hline \multirow{2}{*}{$\Pi-2$} & листья & $13,8 \pm 0,1$ & $29,3 \pm 3,8$ & $6,3 \pm 0,5$ & $49,4 \pm 0,9$ \\
& корни & $2,9 \pm 0,0$ & $25,2 \pm 0,0$ & $13,9 \pm 0,4$ & $42,0 \pm 1,5$ \\
\hline
\end{tabular}

Примечание: П-1 - с. Большая Каменка, П-2 - п. Серноводск, ГЛ - фракция гликолипидов, ФЛ - фракция фосфолипидов, НЛ - фракция нейтральных липидов, Л - липиды.

Данное обстоятельство может быть связано с тем, что P. salsa является представителем галофитов, свойством которых является их способность накапливать соли в клетках растений. Это предполагает увеличение поверхности мембранной сети и количества структурных компонентов. В корнях разница во фракционном составе была менее существенной.

По относительному содержанию индивидуальных компонентов ГЛ - моногалактозилдиацилглицеринов (МГДГ), дигалактозилдиацилглицеринов (ДГДГ) - и сульфохиновозилдиацилглицеринов (СХДГ) в листьях и корнях растений достоверных различий не выявлено (рис. 4).

Более чувствительным к условиям произрастания, в отличие от ГЛ, были ФЛ. Например, вклад ФХ в пул ФЛ листьев был в 1,5 выше, чем в растениях П-2, а относительное содержание фосфатидилэтаноламина (ФЭ), напротив, было выше в растениях П-1. В корнях более изменчивыми компонентами были ФЭ и ФГ.
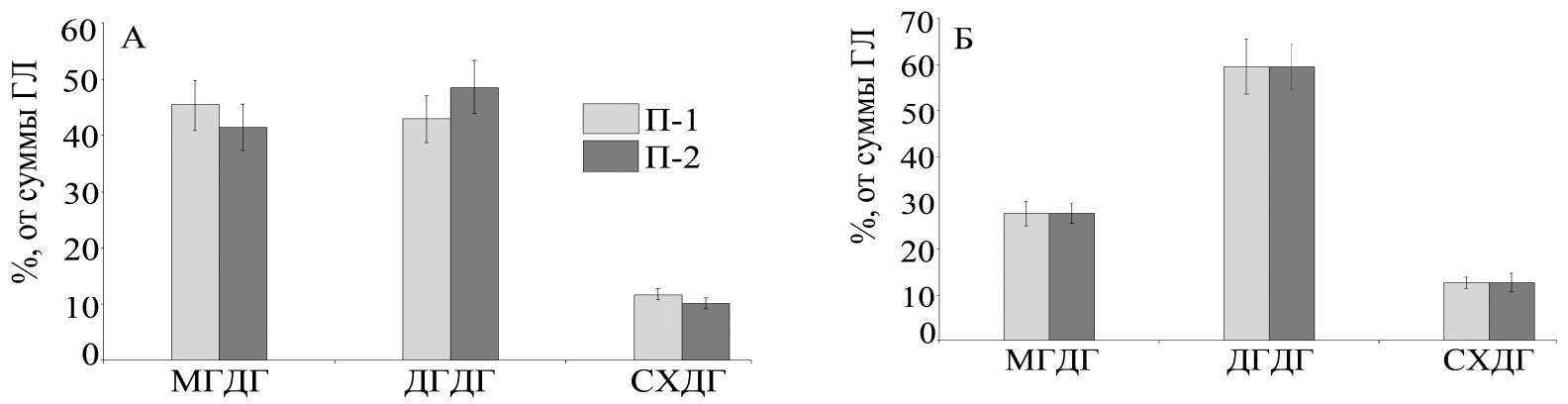

Рис. 4. Состав гликолипидов в листьях (А) и корнях (Б) растений $P$. salsa, произрастающих на двух площадках. МГДГ - моногалактозилдиацилглицерины, ДГДГ - дигалактозилдиациглицерины, СХДГ сульфохиновозилдиацилглицерины 

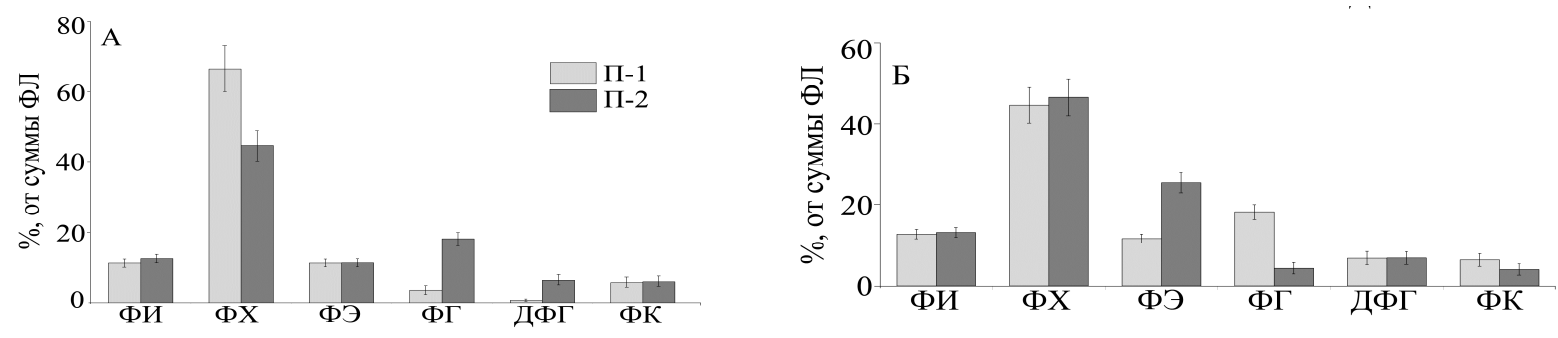

Рис. 5. Содержание фосфолипидов в листьях (А) и корнях (Б) растений $P$. salsa, произрастающих на двух площадках: ФХ - фосфатидилхолины, ФГ - фосфатидилглицерины, ФИ - фосфатидилинозиты, ФЭ фосфатидилэтаноламины, ДФГ - дифосфатидилглицерины, ФК - фосфатидная кислота

Энергетическим и метаболическим запасом клетки являются НЛ. Их состав представляли триацилглицерины (ТАГ) и диацилглицерины (ДАГ) - сложные эфиры глицерина и карбоновых кислот, эфиры стеринов (ЭСт), Ст - полициклические соединения, являющиеся предшественниками стероидных гормонов и витаминов, а также свободными жирными кислотами (СЖК), спиртами (Сп) и восками (Вс). В листьях растений преобладающими компонентами были ДАГ и ЭСт, а в корнях - ТАГ и ЭСт. Для большинства компонентов существенных различий, связанных с условиями произрастания, не обнаружено как в корнях, так и в листьях (рис. 6).

Сравнение данных количественного содержания исследуемых компонентов показало, что распределение полисахаридов, фенольных соединений, аскорбиновой кислоты и липидов является органоспецифичным и зависит от условий произрастания, в частности от влажности и солености почвы. Значения коэффициентов вариации, характеризующих изменчивость содержания компонентов, варьируют от $6,3 \%$ до $68 \%$ в листьях и от $1,5 \%$ до $47 \%$ в корнях (рис. 7). Если в листьях наиболее вариативным показателем является содержание аскорбиновой кислоты, то в корнях таким свойством обладают ВРПС. В листьях к менее вариативным компонентам можно отнести содержание общего количества полисахаридов, включая фракции ВРПС, ГЦ А, и ГЛ. В корнях же к числу наименее изменчивых по концентрации компонентов относятся полисахариды, фракция ГЦ А и общее количество липидов.
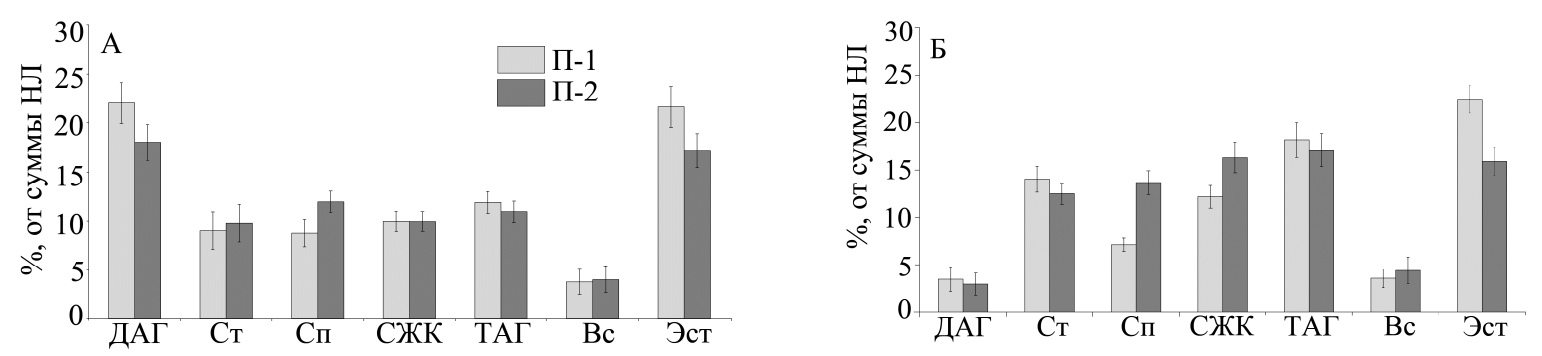

Рис. 6. Содержание нейтральных липидов в листьях (А) и корнях (Б) растений $P$. salsa, произрастающих на двух площадках: ДАГ - диацилглицерины, Ст - стерины, ТАГ - триацилглицерины, ЭСт - эфиры стеринов, Сп - спирты, СЖК - свободные жирные кислоты, Вс - воски


Рис. 7. Значения коэффициентов вариации количественных показателей исследуемых компонентов в листьях (А) и корнях (Б) 
Таким образом, на примере растений $P$. salsa, имеющих филогененическое родство со многими лекарственными растениями рода Plantago, установлены особенности изменчивости компонентов, способных проявлять биологическую активность. Выявлены наиболее и наименее вариативные компоненты в листьях и корнях. Установлено, что распределение полисахаридов, фенольных соединений, аскорбиновой кислоты и липидов в органах растений зависит от эдафических факторов. Полученные данные могут быть полезны при разработке практических рекомендаций для сбора лекарственных растений в различных условиях произрастания.

\section{Список литературы}

1. Kuiper D., Smid A. Genetic differentiation and phenotypic plasticity in Plantago major the effect of differences in level of irradiance on growth, photosynthesis, respiration and chlorophyll content // Physiol. Plant. 1985. Vol. 65. N4. Pp. 520-528.

2. Peyroux J., Mehri M.H., Plat M., Rossignol P., Velette G. Plantago arenaria Waldst. \& Kit. Isolation of narcotin and a new alkaloid arenaine // Ann. Pharm. Fr. 1972. Vol. 30. Pp. 51-54.

3. Murai M., Tamayama Y., Nishibe S. Phenylethanoids in herb of Plantago lanceolata and inhibitory effect on arachidonic acid-induced mouse // Plant Med. 1995. Vol. 61. N5. Pp. 479-480.

4. Haznagy A. Recents results with Plantaginis folium (Plantain) leaves // Herba Hung. 1970. Vol. 9. Pp. 57-63.

5. Bogdanova E.S., Grebenkina T.M., Nesterov V.N., Rozentsvet O.A. Biologically active compounds from representatives of the family Plantaginaceae // Chem. Nat. Comp. 2014. Vol. 50. N6. Pp. 1001-1004.

6. Kawashty S.A., Gamal E.D., Abdalla M.F., Saleh N.A.M. Flavonoids of Plantago species in Egypt // Biochem. System. Ecol. 1994. Vol. 22. N7. Pp. 729-733.

7. Мисин В.М., Сажина Н.Н., Завьялов А.В. Сезонная динамика изменения содержания антиоксидантов фенольного типа в листьях подорожника и одуванчика // Химия растительного сырья. 2010. №3. С. 103-106.

8. Сажина Н.Н., Мисин В.М. Измерение суммарного содержания фенольных соединений в различных частях лекарственных растений // Химия растительного сырья. 2011. №3. С. 149-152.

9. Taskova R., Evstatieva N., Handjieva N., Popov S. Iridoid patterns of genus Plantago L. and their systematic significance // Z. Naturforsch. C. 2002. Vol. 57, N1-2. Pp. 42-50.

10. Biringanine G., Ouedraogo M., Vray B., Samuelsen A., Duez P. Partial chemical characterization of immunomodulatory polysaccharides from Plantago palmata Hook. f. s. leaves // Inter. J. Carboh. Chem. 2014. Vol. 2012. Pp. 1-7.

11. Оленников Д.Н., Samuelsen A.В., Танхаева Л.М. Подорожник большой (Plantago major L.). Химический состав и применение // Химия растительного сырья. 2007. №2. С. 37-50.

12. Samuelsen A.B. The traditional uses, chemical constituents and biological activities of Plantago major L. A review // J. Ethnopharmacol. 2000. Vol. 71. N1-2. Pp. 1-21.

13. Гордеец А.В., Седулина О.Ф., Черникова А.А., Ерохина Л.Г. Plantago ovata (Мукофальк®) в терапии гастритов при иерсиниозах // Гастроэнтерология Санкт-Петербурга. 2010. №2-3. С. 13-14.

14. Fons F., Gargadennec A., Rapior S. Culture of Plantago species as bioactive components resources: a 20-year review and recent applications // Acta Bot. Gallica. Bot. Let. 2008. Vol. 155. N2. Pp. 277-300.

15. Аринушкина Е.В. Руководство по химическому анализу почв. М., 1970. 487 с.

16. Гребенкина Т.М., Нестеров В.Н., Розенцвет О.А., Богданова Е.С. Изменение состава липидов и пигментов Plantago media (Plantaginaceae) в течение светлого времени суток // Растительные ресурсы. 2012. Вып. 4. C. 565-578.

17. Краснов Е.А., Березовская Т.П., Алексеюк Н.В. Выделение и анализ природных биологически активных веществ. Томск, 1987. $189 \mathrm{c.}$

18. Кочетков Н.К. Химия биологически активных соединений. М., 1970. 631 с.

19. Государственная фармакопея СССР. Вып. 2. Общие методы анализа. Лекарственное растительное сырье МЗ СССР. 11-е изд. М., 1989. 400 с.

20. Сычев И.А., Смирнов В.М. Состояние селезенки крыс при действии полисахаридов донника желтого (пектина) // Вестник РГМУ. 2004. №6. С. 85-95.

21. Лобанова А.А., Будаева В.В., Сакович Г.В. Исследование биологически активных флавоноидов в экстрактах из растительного сырья // Химия раститительного сырья. 2004. №1. С. 47-52.

22. Cheng S.-Y., Xu F., Wang Y. Advances in the study of flavonoids in Ginkgo biloba // J. Medic. Plants Res. 2009. Vol. 3. N13. Pp. 1248-1252.

23. Minakshi M.S., Mulchand S.A., Deul K.B., Nayna J.M. Herbosomes: herbo-phospholipid complex an approach for absorption enhancement // Intern. J. Biol. Pharm. Res. 2012. Vol. 3. N8. Pp. 946-955.

24. Ердакова В.П. Теоретические и практические основы конструирования современных космецевтических средств, обладающих трансдермальной активностью. Бийск, 2008. 326 с.

25. Yankah V.V. Phytosterols and human health / Handbook of functional lipids (Functional foods and nutraceuticals) / In C.C. Akoh (ed.). 1995. Boca Raton, London, New York, Singapore. Pp. 403-414.

Поступило в редакиию 24 мая 2016 г. 
Grebenkina T.M., Bogdanova E.S.*, Nesterov V.N., Rozentsvet O.A. VARIATIONS OF BIOLOGICALLY ACTIVE COMPOUNDS IN DIFFERENT ORGANS PLANTAGO SALSA PALL. DEPENDING ON THE GROWING CONDITIONS

Institute of Ecology of Volga Basin of Russian Academy of Sciences, ul. Komzina, 10, Togliatti, 445003 (Russia), e-mail:cornales@mail.ru

The quantitative variations of compound contents capable of developing biological activity (polysaccharides, phenolic compounds, lipids and ascorbic acid) in the leaves and roots of Plantago salsa halophyte depending on vegetation conditions have been explored. The hemicellulose A fraction prevailed among the polysaccharides followed by hemicellulose B fraction, pectin substances and water-soluble polysaccharides in order of decreasing. The membranous and spare glycerpolipids composed the primary group of lipids. The concentration of phenolic compounds was much higher in the leaves than in the roots. The content and the ratio of phenolic compounds and ascorbic acid varied depending on vegetation conditions. The distribution of polysaccharides, phenolic compounds, ascorbic acid and lipids in the organs of plants depends on the edaphic factors. The most and the least variable concentrations of compounds have been revealed in the leaves and the roots of the plants. The collected data can be useful in elaboration of practical recommendations for picking medicinal plants in different vegetation conditions.

Keywords: ascorbic acid, lipids, polysaccharides, Plantago salsa.

\section{References}

1. $\quad$ Kuiper D., Smid A. Physiol. Plant., 1985, vol. 65, no. 4, pp. 520-528.

2. Peyroux J., Mehri M.H., Plat M., Rossignol P., Velette G. Ann. Pharm. Fr., 1972, vol. 30, pp. 51-54.

3. Murai M., Tamayama Y., Nishibe S. Plant Med., 1995, vol. 61, no. 5, pp. 479-480.

4. Haznagy A. Herba Hung., 1970, vol. 9, pp. 57-63.

5. Bogdanova E.S., Grebenkina T.M., Nesterov V.N., Rozentsvet O.A. Chem. Nat. Comp., 2014, vol. 50, no. 6, pp. 1001-1004.

6. Kawashty S.A., Gamal E.D., Abdalla M.F., Saleh N.A.M. Biochem. System. Ecol., 1994, vol. 22, no. 7, pp. $729-733$.

7. Misin V.M., Sazhina N.N., Zav'ialov A.V. Khimiia rastitel'nogo syr'ia, 2010, no. 3, pp. 103-106. (in Russ.).

8. Sazhina N.N., Misin V.M. Khimiia rastitel'nogo syr'ia, 2011, no. 3, pp. 149-152. (in Russ.).

9. Taskova R., Evstatieva N., Handjieva N., Popov S. Z. Naturforsch. C., 2002, vol. 57, no. 1-2, pp. 42-50.

10. Biringanine G., Ouedraogo M., Vray B., Samuelsen A., Duez P. Inter. J. Carboh. Chem., 2014, vol. 2012, pp. 1-7.

11. Olennikov D.N., Samuelsen A.B., Tankhaeva L.M. Khimiia rastitel'nogo syr'ia, 2007, no. 2, pp. 37-50. (in Russ.).

12. Samuelsen A.B. J. Ethnopharmacol, 2000, vol. 71, no. 1-2, pp. 1-21.

13. Gordeets A.V., Sedulina O.F., Chernikova A.A., Erokhina L.G. Gastroenterologiia Sankt-Peterburga, 2010, no. 2-3, pp. 13-14. (in Russ.).

14. Fons F., Gargadennec A., Rapior S. Acta Bot. Gallica. Bot. Let., 2008, vol. 155, no. 2, pp. 277-300.

15. Arinushkina E.V. Rukovodstvo po khimicheskomu analizu pochv. [Guide to Chemical analysis of soil]. Moscow, 1970, 487 p. (in Russ.).

16. Grebenkina T.M., Nesterov V.N., Rozentsvet O.A., Bogdanova E.S. Rastitel'nye resursy, 2012, no. 4, pp. $565-578$. (in Russ.).

17. Krasnov E.A., Berezovskaia T.P., Alekseiuk N.V. Vydelenie i analiz prirodnykh biologicheski aktivnykh veshchestv. [Isolation and analysis of natural biologically active substances]. Tomsk, 1987, 189 p. (in Russ.).

18. Kochetkov N.K. Khimiia biologicheski aktivnykh soedinenii. [Chemistry of biologically active compounds]. Moscow, 1970, 631 p. (in Russ.).

19. Gosudarstvennaia farmakopeia SSSR. Vyp. 2. Obshchie metody analiza. Lekarstvennoe rastitel'noe syr'e MZ SSSR. [State Pharmacopoeia of the USSR. Vol. 2. General methods of analysis. Medicinal plant material of the USSR Ministry of Health]. Moscow, 1989, 400 p. (in Russ.).

20. Sychev I.A., Smirnov V.M. Vestnik RGMU, 2004, no. 6, pp. 85-95. (in Russ.).

21. Lobanova A.A., Budaeva V.V., Sakovich G.V. Khimiia rastititel'nogo syr'ia, 2004, no. 1, pp. 47-52. (in Russ.).

22. Cheng S.-Y., Xu F., Wang Y. J. Medic. Plants Res., 2009, vol. 3, no. 13, pp. 1248-1252.

23. Minakshi M.S., Mulchand S.A., Deul K.B., Nayna J.M. Intern. J. Biol. Pharm. Res., 2012, vol. 3, no. 8, pp. $946-955$.

24. Erdakova V.P. Teoreticheskie i prakticheskie osnovy konstruirovaniia sovremennykh kosmetsevticheskikh sredstv, obladaiushchikh transdermal'noi aktivnost'iu. [Theoretical and practical bases of designing modern cosmeceutical having transdermal activity]. Biisk, AltGTU, 2008, 326 p. (in Russ.).

25. Yankah V.V. Phytosterols and human health. Handbook of functional lipids (Functional foods and nutraceuticals), ed. C.C. Akoh. 1995, Boca Raton, London, New York, Singapore, pp. 403-414. 
